\title{
Sensory complement model helps to predict diel alarm response patterns in juvenile Atlantic salmon (Salmo salar) under natural conditions
}

\author{
Antoine O.H.C. Leduc, Jae-Woo Kim, Camille J. Macnaughton, and Grant E. Brown
}

\begin{abstract}
Fish rely on both chemical and visual cues to evaluate predation risk. Decisions with respect to activity partitioning in time (i.e., night vs. day) rely on accurate assessment of predation risk relative to energy intake; predation risk is generally thought to be lower at night at the expense of feeding opportunities. At night, the sensory complement model predicts greater reliance on chemical perception of risk. Under this condition, a lower ability to use vision should result in a more conservative response to chemical cues than during the day. We tested this hypothesis under natural conditions by comparing the alarm response of young-of-the-year Atlantic salmon (Salmo salar L., 1758) under summer day and night conditions in salmon nursery streams. We found that salmon responded to the alarm cues to a significantly greater extent at night. This suggests that the sensory complement model may be correct and that nocturnal perception of risk may be generally higher than previously believed for juvenile salmon in the wild. In the absence of a more precise indicator of risk (e.g., vision), a greater reliance on chemosensory risk assessment at night may cause fish to shift to more risk-adverse behaviour.
\end{abstract}

Résumé : Les poissons utilisent à la fois les signaux chimiques et visuels pour évaluer le risque de prédation. Les décisions relatives au partitionnement de l'activité dans le temps (c.-à-d., entre la nuit et le jour) dépendent d'une évaluation précise du risque de prédation en fonction de l'apport d'énergie; on croit généralement que le risque de prédation est plus faible la nuit, au détriment du nombre d'occasions de s'alimenter. Le modèle de complémentarité sensorielle prédit une plus grande dépendance de la perception chimique des risques durant la nuit. Dans cette situation, la capacité réduite à utiliser la vision devrait entraîner une réaction plus conservatrice aux signaux chimiques que durant la journée. Nous testons cette hypothèse dans des conditions naturelles en comparant la réaction d'alerte chez de jeunes saumons atlantiques de l'année (Salmo salar L., 1758) dans des conditions de jour et de nuit en été dans des cours d'eau de nourricerie de saumons. Les saumons réagissent significativement plus aux signaux d'alerte la nuit. Cela laisse croire que le modèle de complémentarité sensorielle s'applique et que la perception du risque durant la nuit peut être plus importante qu'on ne le croyait antérieurement chez de jeunes saumons en nature. En l'absence d'un indicateur plus précis du risque (par ex., la vision), une dépendance plus grande de l'évaluation chimiosensorielle du risque la nuit peut amener les poissons à adopter un comportement qui entraîne moins de risques.

[Traduit par la Rédaction]

\section{Introduction}

Animal species have evolved different diel activity rhythms that are of adaptive value (reviewed in Kronfeld-Schor and Dayan 2003). Food availability and (or) predation risk may vary under predictable diel modes so that many animals face decisions about when is the most advantageous time to be active or cryptic. In this context, the optimal time for being active (i.e., that maximizes survival) should be the time of day at which $\mu / f$ is minimized, where $\mu$ represents instantane-

Received 22 September 2009. Accepted 22 February 2010.

Published on the NRC Research Press Web site at cjz.nrc.ca on 16 March 2010.

A.O.H.C. Leduc. ${ }^{1}$ Aquatic Ecology Research Laboratories, The University of British Columbia, 2201 Main Mall, Vancouver, BC V6J 2J2, Canada.

J.-W. Kim, C.J. Macnaughton, and G.E. Brown. Department of Biology, Concordia University, 7141 Sherbrooke St. West, Montréal, QC H4B 1R6, Canada.

${ }^{1}$ Corresponding author (e-mail: a.leduc@ fisheries.ubc.ca). ous mortality risk and $f$ represents feeding rate (Metcalfe et al. 1999). In many animal species, individuals active at night should face lower predation risks but at the expense of reduced feeding efficiency (Åbjörnsson et al. 1997; Fraser and Metcalfe 1997; Metcalfe et al. 1999; Orpwood et al. 2006). Similarly, responding to a threat should aim to minimize the $\mu / f$ ratio. At night, because the benefits of feeding may be reduced for visual foragers (reduced values of $f$ ), prey should be more conservative in their response to threats even if the risk level is comparable to daytime.

Juvenile salmonids are unusually flexible in partitioning of diel activity so that their activity budget is not restricted to a single period of light intensity (Fraser et al. 1995; Breau et al. 2007). For example, Atlantic salmon (Salmo salar L., 1758) are exclusively nocturnal during winter (Cunjak 1988; Fraser et al. 1993) and at low summer temperatures (Fraser et al. 1995), while diurnal activity is more often found under higher temperatures (Breau et al. 2007). This shift to nighttime activity in cold-water conditions is attributed to lowered metabolic demand and reduced escape abilities (Metcalfe et al. 1999). 
Although nocturnal activity may reduce predation risks from diurnal predators and be considered safer overall (Metcalfe et al. 1999), losing the ability to rely on vision to detect nocturnal predators should render predator assessment more difficult, making nocturnal activity risky (Aksnes and Giske 1993; Cerri 1983). This may be especially valid when piscivorous fish predators are also active at night as to reduce the risks associated with daytime activity (Cerri 1983; Fraser and Metcalfe 1997).

The availability of multiple sensory inputs to detect predators should improve risk assessment, leading to finer tuned threat-sensitive response (Brown and Magnavacca 2003; Ferrari et al. 2008). Lima and Steury (2005) proposed a "sensory complement" hypothesis in which multiple cues of dangers would be used by prey in an additive manner, triggering alarm responses of greater intensity than from any single cue. Waterborne chemicals are also important for detecting predators in fresh water (reviewed in Chivers and Smith 1998; Smith 1999). Such chemical information (hereafter chemical alarm cues) is typically released from the injured skin of prey fish following mechanical damage during a predation event. Given the passive nature of their dispersal and the innate species-typical antipredator response they initiate in nearby conspecifics, chemical alarm cues have been shown to represent a reliable but diffused indication of local predation risk (i.e., providing less details on predator location than more precise cues such as vision). Their benefits during predator encounters demonstrate their importance for prey survival (Chivers and Smith 1998; Mirza and Chivers 2000, 2003; Brown and Chivers 2005).

Between day and night, the sensory complement hypothesis predicts that when visual cues are not available (or of reduced availability), the response to chemical cues may be adjusted up, as it would represent the only available sensory input to detect threats. As such, daytime high-risk situations would be characterized by visual and chemical threats occurring simultaneously, whereas chemical cues alone would be representative of lesser danger levels (Kim et al. 2009). By contrast, as visual cues are greatly limited at night, high-risk situations may be recognized from chemical threat occurring alone (Hartman and Abrahams 2000). Under nighttime conditions, as prey cannot fine tune the response to chemical cues based on visual information, they should respond at a higher intensity. As previously suggested, under nighttime conditions the level of safety may be higher for young-of-the-year (YOY) salmon. If perceived as such, the motivation to perform threat-sensitive behaviour may be reduced so that the intensity of an alarm response should not be different between day and night.

The goal of this study is to assess under natural conditions the response of juvenile Atlantic salmon exposed to chemical alarm cues under day or night conditions. We tested the sensory complement model from conditions where visual cues are available to prey (day) to when they are limited (night). Specifically, does reduced visual acuity translate into increased sensitivity to chemical information? From the sensory complement model, at night we predict increased response to chemical cues to occur because no significant source of visual information exists and feeding efficiency is reduced (Fraser and Metcalfe 1997). Alternatively, if nighttime activity is perceived as safer, then even when deprived of vision, prey may not respond more heavily to chemosensory cues. In this context, we predict that if YOY salmon perceive nighttime activity to be less risky (against potential feeding benefits) their response to alarm cues should be equal or lower than under daytime conditions. We chose YOY Atlantic salmon to conduct this study given their high level of site-fidelity behaviour (Steingrímsson and Grant 2003), making field observations easily feasible under natural conditions and YOY salmon may display comparable levels of activity under both daytime and nighttime conditions (Imre and Boisclair 2004).

\section{Materials and methods}

\section{Test sites}

This experiment was conducted between 10 and 21 July 2006 in Catamaran Brook and Little Southwest Miramichi River, both located in Northcumberland County, New Brunswick, Canada (approximately $46^{\circ} 51^{\prime} \mathrm{N}, \quad 66^{\circ} 09^{\prime} \mathrm{W}$ ). These close proximity waterways are natural spawning habitat for wild Atlantic salmon and are surrounded by mature forest suffering little direct human disturbance effects with a complete absence of light pollution (Cunjak et al. 1993; Johnston 1997; A.O.H.C. Leduc, personal observations). In each of these streams, a site of approximately $200 \mathrm{~m}^{2}$ was chosen to conduct behavioural observation trials (see below). Site characteristics (depth, water temperature, current velocity, and substrate complexity; Table 1) were recorded at the end of behavioural trials (see below). Aside from Atlantic salmon, other fish species were encountered in the study sites, including brook trout (Salvelinus fontinalis (Mitchill, 1814)), blacknose dace (Rhinichthys atratulus (Hermann, 1804)), threespine stickleback (Gasterosteus aculeatus L., 1758), American eel (Anguilla rostrata (Lesueur, 1817)), and slimy sculpin (Cottus cognatus Richardson, 1836). Of these species, American eel and brook trout are known to prey on juvenile Atlantic salmon (Scott and Crossman 1973). Nonfish predators were also observed to be active in or near test sites, including Belted Kingfisher (Megaceryle alcyon (L., 1758)) and Common Merganser (Mergus merganser L., 1758).

\section{Stimulus collection}

Alarm-cue solution was generated by homogenizing the skin of 14 Atlantic salmon donors (standard length range: 3.43-4.12 mm). After their capture, donors were euthanized via cervical dislocation (in accordance with Concordia University Animal Care protocol No. AREC-2005-BROW). Skin fillets were removed from either side of donor fish and immediately placed into unchlorinated chilled well water. Fillets were then homogenized, filtered through polyester filter floss, and diluted to the desired final volume with the addition of untreated well water. We collected sufficient skin so that the alarm-cue solution was made with approximately $0.08 \mathrm{~cm}^{2}$ of skin per millilitre of solution. This area of skin per water volume has previously been shown to reliably elicit antipredator responses in juvenile Atlantic salmon under natural conditions (Leduc et al. 2007; Kim et al. 2009). The resulting alarm-cue solution was packaged in $20 \mathrm{~mL}$ aliquots and frozen until needed. As a control, we used stream water. 


\section{Experimental protocol}

For this experiment, we observed YOY salmon behaviour in their habitat. Observations were conducted under daytime (between 1100 and 1500) and nighttime (between 2230 and 0200) conditions. Sunrise and sunset occurred at approximately 0551 and 2108, respectively, during the study period. After a salmon was haphazardly found by the observer (A.O.H.C.L.) while snorkeling within the test sites, the observer positioned himself approximately $1.5 \mathrm{~m}$ upstream from the test fish at an angle of $45^{\circ}$ relative to the water current (upstream but to the left or right of the test fish to reduce the formation of artificial turbulences). We located focal fish by moving upstream and spacing sites of salmon observation by approximately $4 \mathrm{~m}$ (i.e., larger than the $1.5-3 \mathrm{~m}^{2}$ territory size typical of YOY salmon; Steingrímsson and Grant 2003). Behavioural observations were video-recorded using underwater Sea View ${ }^{\mathrm{TM}}$ camera held by the observer. After a test fish appeared acclimated to the observer's presence (i.e., it was moving and feeding), we started the observation trials. Observation trials consisted of one 5 min baseline behaviour (prestimulus period) followed by a $5 \mathrm{~min}$ postinjection (poststimulus period). Between baseline and postinjection periods, we randomly injected one of two treatments, either chemical alarm cues or water (control). We used $60 \mathrm{~mL}$ syringes handheld by the observer (as in Leduc et al. 2007) to inject either of the two stimuli. For the nighttime trials, we used a low-light Sea View ${ }^{\mathrm{TM}}$ camera for filming under low-light conditions. To ensure that the observer was aiming the camera in the direction of the focal fish, we used a handheld white light (as in Imre and Boisclair 2004) pointed upward by the observer (to reduced potential effects on activity; Gries et al. 1997) having a power of approximately $30 \mathrm{~lm}$. Fish did not appear disturbed by the light, as they were displaying similar activity pattern during both daytime and nighttime. For each combination of treatments, 18 observations were completed for a total of 72 observations (18 observations $\times 2$ stimuli $\times 2$ testing periods).

After observations trials were conducted, we measured current speed (taken at the middle of the water column using a Flo-Mate velocity meter; Marsh McBirney Inc., Frederick, Maryland, USA), depth, water temperature, and substrate complexity. Substrate complexity was determined by using a $1 \mathrm{~m}$ long flexible metal wire that we molded to the substrate at the focal location of each test subject (i.e., the location where they received the stimulus). A value was obtained by averaging two measurements of the linear distance between the ends of the wire after it was molded to the substrate parallel and perpendicular to water flow (as in Keeley and Grant 1995). Because the metal wire had a length of $1 \mathrm{~m}$, a substrate complexity value of one would indicate that the substrate is flat (i.e., no complexity), while a lower number would indicate greater complexity. We averaged theses environmental values obtained in the daytime and nighttime trials and compared these between testing periods and stimulus types (Table 1).

\section{Statistical analysis and behavioural measures}

Using video recordings, we quantified the time spent moving ( $\mathrm{s}$ ) and the number of foraging attempts during prestimulus and poststimulus observation periods. Time spent moving was defined as any observable displacements ex- ceeding one body length. Feeding attempts were defined as any pecking motion typical of salmon striking at drifting or benthic prey items. We compared the intensity of each of these two behaviour by subtracting the prestimulus scores from poststimulus scores (poststimulus - prestimulus) giving us a difference score ( $\Delta$ stimulus) for each behaviour. These two scores were used as dependant variables in all subsequent analyses (i.e., foraging and moving). All behavioural measurements were conducted by the same observer from a 32 inch $(82 \mathrm{~cm})$ Sony ${ }^{\mathrm{TM}}$ flat-screen monitor without any prior knowledge of the stimulus treatment. We also identified and counted potential predatory fish species that passed in the field of view of the camera.

Using a $2 \times 2$ design, we tested for the overall effects of two factors (stimulus types (i.e., alarm cues vs. water) and testing period (i.e., daytime vs. nighttime)) on both behavioural measures using multivariate analysis of variances (MANOVAs). To further understand any observed changes in response, we performed post hoc comparisons using ANOVAs taking each factor separately. To determine whether the behavioural responses were influenced by differences in habitat characteristics between streams, we compared the physical parameters using an analysis of variance (ANOVA) (Table 1). To ensure that baseline activity was similar among test fish between stimuli, we also used an ANOVA and compared the prestimulus values of each behavioural measure. Our data met the assumption of normality. All statistical analyses were conducted using SPSS version 13 (SPSS Inc., Chicago, Illinois, USA).

\section{Results}

Our main MANOVA results revealed a significant effect of stimuli and testing period on the intensity of the behavioural responses measured (stimuli: $F_{[3,71]}=4.650, P=$ 0.014; testing period: $F_{[3,71]}=7.650, P=0.012$ ). Post hoc tests revealed that alarm cues elicited significant reductions in feeding attempts and time spent moving under daytime (feeding attempts during the day: $F_{[1,34]}=6.640, P=0.010$; time spent moving during the day: $F_{[1,34]}=7.972, P=$ 0.032; Fig. 1) and nighttime (feeding attempts at night: $F_{[1,34]}=12.556, P=0.001$; time spent moving at night: $F_{[1,34]}=11.834, P=0.008$; Fig. 1) conditions compared with water (control). Baseline activity was significantly lower at night for feeding attempts $\left(F_{[1,34]}=8.501, P=\right.$ $0.001)$ and time spent moving $\left(F_{[1,34]}=6.602, P=0.011\right)$. Interestingly, under alarm-cue treatments, a significant difference existed between testing periods for $\Delta$ stimulus in feeding attempts $\left(F_{[1,34]}=4.708, P=0.017\right)$ and in time spend moving $\left(F_{[1,34]}=7.912, P=0.043\right)$, suggesting an increased alarm response at night (Fig. 1). For stream water (control) treatments, no difference existed in $\Delta$ stimulus scores between daytime and nighttime in neither feeding $\left(F_{[1,34]}=0.287, P=0.595\right)$ nor moving $\left(F_{[1,34]}=0.093, P=\right.$ $0.881)$, suggesting that salmon did not respond to water injections during either period. No difference in baseline activity existed between stimulus treatments under both daytime and nighttime conditions for feeding attempts (daytime: $F_{[1,34]}=0.301, P=0.377$; nighttime: $F_{[1,34]}=$ $0.199, P=0.659$ ) and time spent moving (daytime: $F_{[1,34]}=$ 1.504, $P=0.591$; nighttime: $\left.F_{[1,34]}=0.251, P=0.876\right)$. 
Table 1. Results of the one-way analysis of variance (ANOVA) used to assess differences in the surveyed variables between testing period (daytime vs. nighttime) and between stimulus type (water vs. alarm cue) for juvenile Atlantic salmon (Salmo salar).

\begin{tabular}{|c|c|c|c|c|c|c|c|c|c|c|}
\hline & \multicolumn{5}{|c|}{ Testing period } & \multicolumn{5}{|c|}{ Stimulus type } \\
\hline & Daytime & Nighttime & $F$ & $\mathrm{df}$ & $p$ & Water & Alarm cue & $F$ & $\mathrm{df}$ & $p$ \\
\hline Depth (m) & $28.46 \pm 1.92$ & $34.78 \pm 2.8$ & 3.379 & 1,71 & 0.052 & $32.12 \pm 2.44$ & $31.15 \pm 2.50$ & 1.503 & 1,71 & 0.484 \\
\hline Velocity $\left(\mathrm{m} \cdot \mathrm{s}^{-1}\right)$ & $17.09 \pm 1.21$ & $16.34 \pm 1.41$ & 0.227 & 1,71 & 0.986 & $15.87 \pm 1.21$ & $16.81 \pm 1.29$ & 0.275 & 1,71 & 0.880 \\
\hline Temperature $\left({ }^{\circ} \mathrm{C}\right)$ & $19.2 \pm 0.17$ & $18.4 \pm 0.14$ & 17.391 & 1,71 & $0.010 *$ & $19.2 \pm 0.14$ & $19.1 \pm 0.17$ & 0.099 & 1,71 & 0.908 \\
\hline Substrate complexity & $87.0 \pm 0.18$ & $83.8 \pm 0.26$ & 2.044 & 1,71 & 0.069 & $84.9 \pm 0.20$ & $86.7 \pm 0.21$ & 1.034 & 1,71 & 0.192 \\
\hline
\end{tabular}

Note: Values are means $\pm \mathrm{SD}$. An asterisk indicates significance at $P \leq 0.05$.

Fig. 1. Differences $(\Delta$ stimulus; mean $\pm \mathrm{SE})$ in $(a)$ number of feeding attempt and (b) time spent moving (s) for juvenile Atlantic salmon (Salmo salar) exposed to either alarm cues (shaded bars) or stream water (open bars) during daytime or nighttime. Asterisks indicate significant difference $(P \leq 0.05)$.
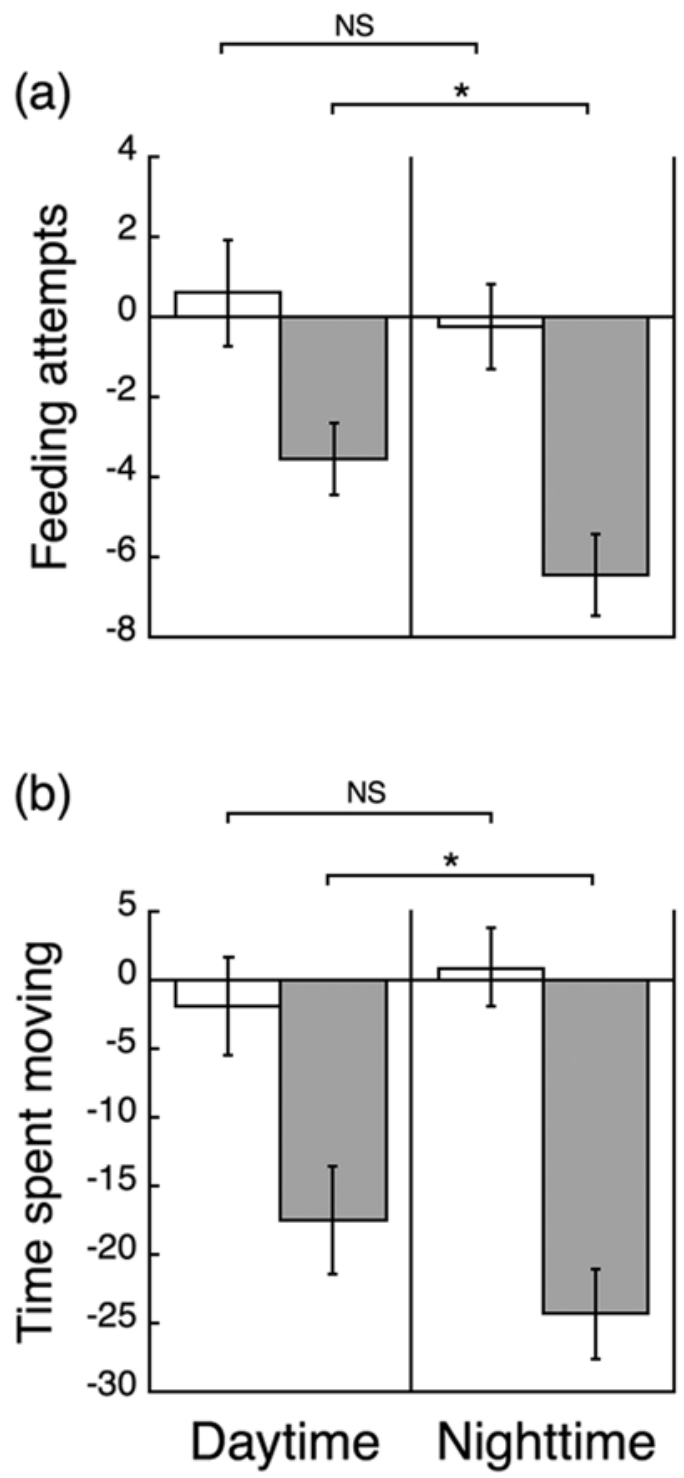

ANOVA tests between stimuli and testing periods showed no physical variable difference between stimulus treatments; however, under nighttime condition, there was a slight but significant difference in water temperature (Table 1).
Although anecdotal, under daytime trials we counted (from the video recordings) only one brook trout, whereas under nighttime trials we counted six brook trout and two American eels, suggesting that piscivorous fish may be more active at night.

\section{Discussion}

These results show that under natural summer conditions, YOY salmon response to chemical alarm cues may vary in intensity in a context-specific manner that depended on photoperiod. Chemical alarm cues elicited significantly greater alarm response at night compared with otherwise similar daytime conditions (with the obvious exception of reduced light intensity at night). This suggests that the intensity of an alarm response may be in function of the intensity of risk perceived from all available sensorial inputs. At night, chemosensorial risk assessment is likely the only available sensorial input for juvenile salmon that cannot rely on vision to mediate risk. During this time, detecting chemical information of risk may convey the "maximal" indication of danger, whereas under daytime conditions, information about a risk of similar intensity would be detected from visual and chemical cues occurring simultaneously (Smith and Belk 2001). This is consistent with the sensory complement shypothesis whereby lowered response occurred when only one of two possible sensorial inputs detected a threat (i.e., under daytime condition). Several studies have tested the threat-sensitivity hypothesis, predicting maximal alarm sresponse when multiple cues of danger occurred simultaneously (Helfman 1989; Hartman and Abrahams 2000; Smith and Belk 2001). Under natural conditions, Kim et al. (2009) demonstrated significantly higher response in juvenile Atlantic salmon when visual and chemical cues were presented simultaneously. Our results extrapolate from previous findings by showing a context-dependant response to a single cue of danger from a change in the availability of sensorial inputs.

The difference in intensity of the alarm response between day and night is reflected by an attempt to minimize the risk of mortality against potential feeding benefits $(\mu / f)$. At night, the intensity of the alarm response to chemical alarm cues is greater, suggesting that this period may not necessarily be considered safer than daytime ( $\mu$ may not change). Although only anecdotally, we observed more potential fish predators (adult brook trout and American eels) at night, suggesting that the overall level of predation risk may not be significantly lower than during the day (Cerri 1983). However, nighttime feeding efficiency has been estimated to be only $10 \%$ of daytime (Fraser and Metcalfe 1997). Thus, the benefits of conspicuous activity (i.e., feeding) are arguably lower at night, increasing the benefits of responding to a danger 
with greater intensity. It seems reasonable to argue that nighttime risk assessment may be more "manageable" for YOY salmon. Indeed, compared with daytime during which avian predators are commonly active (Wood 1987; Metcalfe et al. 1999), the use of alarm cues (visual or chemical) may not be effective to detect and avoid predation. Avian predators may travel distances far greater than the range of predator detection of YOY salmon, striking suddenly and successfully on small prey fishes (A.O.H.C. Leduc, personal observations). Inversely at night, active predators (i.e., piscivorous fish and mammals) may only strike from closer distances, likely making local risk assessment more effective for detecting dangers. In such cases, the ecological relevance of chemical risk assessment is likely to be within ranges that juvenile salmon can monitor, having direct benefits on individual survival. Although we realize that the low number of predatory fish observed in our video recordings is not necessarily a precise estimate of overall predator density, it should nevertheless represent a simple measure of predatory fish activity in the study sites surveyed. As suggested by Metcalfe et al. (1999) and Cerri (1983), piscivorous fish activity may be safer at night, given their main predators would be diurnally active and predation risk may be monitored with more efficiency.

Salmon may not survive their first winter, unless they reach a threshold size (Smith and Griffith 1994). Hence, to grow as quickly as possible, YOY salmonids are expected to take greater risks (i.e., forage under both daytime and nighttime). In this experiment, temperature was likely not a trigger of exclusive nighttime foraging behaviour, as our minimum recorded temperature was $18.0{ }^{\circ} \mathrm{C}$. This is within the range reported by Breau et al. (2007) and Imre and Boisclair (2004), showing significant levels of activity in YOY salmon under both daytime and nighttime. Although many studies have surveyed salmon activity between day and night in summer temperatures, comparing our results with those of others requires caution. Here we recorded intensity of activity, whereas other studies reported overall number of individual salmon active (i.e., not sheltering), making differences in "activity" often not comparable. One notable exception to this is from Fraser and Metcalfe (1997), who reported that under starlight illumination salmon reduced feeding by $90 \%$ compared with daytime illumination. Our study showed no such drastic reduction in feeding intensity. Several explanations may account for this difference. First is the fact that our experiment was conducted under natural conditions, potentially reflecting qualitative and quantitative differences in drifting prey between day and night (Flecker 1992). Also, although indirect (i.e., pointing upward toward to water surface), the source of light used to ensure that the camera was aiming at a fish may have been sufficient to slightly boost close-range visual acuity toward drifting or benthic prey items.

In temperate streams, nocturnal activity has typically been associated with reduced predation risk (Metcalfe et al. 1999). Because diel activity is influenced by water temperature (Fraser et al. 1993, 1995; Breau et al. 2007), diel patterns of food availability (Flecker 1992), and risk-assessment abilities, the response to predation must be considered within a larger context of factors that may affect diel activity. Here we show clear evidences for context-dependant response to chemical alarm cues, where under nighttime conditions, the unavailability of visual risk assessment confers chemical risk assessment more importance. Overall, comparable levels of predation risks may exist between day and night, but unlike daytime threats (e.g., birds), nighttime threats (e.g., fishes) are likely easier to detect. This, coupled with reduced feeding efficiency at night, suggest for a more conservative response to chemical alarm cues by juvenile salmonids.

\section{Acknowledgements}

All work reported herein has been conducted in accordance with Concordia University Animal Care protocol No. AC-2005BROW. We thank Neil Metcalfe, Jordan Rosenfeld, and an anonymous reviewer for helpful comments that improved the article. Financial support was provided by Concordia University and the Natural Science and Engineering Research Council of Canada (NSERC) to G.E.B., NSERC Postgraduate Scholarship D2 and the Atlantic Salmon Federation Olin Fellowship to A.O.H.C.L. This paper is contribution No. 113 to the Catamaran Brook Habitat Research Project.

\section{References}

Åbjörnsson, K., Wagner, B.M.A., Axelsson, B.M.A., Bjerselius, R., and Olsén, K.H. 1997. Responses of Acilius sulcatus (Coleoptera: Dytiscidae) to chemical cues from perch (Perca fluviatilis). Oecologia (Berl.), 111(2): 166-171. doi:10.1007/s004420050221.

Aksnes, D.L., and Giske, J. 1993. A theoretical model of aquatic visual feeding. Ecol. Model. 67(2-4): 233-250. doi:10.1016/ 0304-3800(93)90007-F.

Breau, C., Weir, L.K., and Grant, J.W.A. 2007. Individual variability in activity patterns on juvenile Atlantic salmon (Salmo salar) in Catamaran Brook, New Brunswick. Can. J. Fish. Aquat. Sci. 64(3): 486-494. doi:10.1139/F07-026.

Brown, G.E., and Chivers, D.P. 2005. Learning as an adaptive response to predation. In Ecology of predator-prey interactions. Edited by P. Barbosa and I. Castellanos. Oxford University Press, Oxford. pp. 34-54

Brown, G.E., and Magnavacca, G. 2003. Predator inspection behaviour in a characin fish: an interaction between chemical and visual information? Ethology, 109(9): 739-750. doi:10.1046/j. 1439-0310.2003.00919.x.

Cerri, R.D. 1983. The effect of light intensity on predator and prey behaviour in cyprinid fish: factors that influence risk. Anim. Behav. 31(3): 736-742. doi:10.1016/S0003-3472(83)80230-9.

Chivers, D.P., and Smith, R.J.F. 1998. Chemical alarm signaling in aquatic predator-prey systems: a review and prospectus. Ecoscience, 5: 338-352.

Cunjak, R.A. 1988. Behaviour and microhabitat of young Atlantic salmon (Salmo salar) during winter. Can. J. Fish. Aquat. Sci. 45(12): 2156-2160. doi:10.1139/f88-250.

Cunjak, R.A., Caissie, D., El-Jabi, N., Hardie, P., Conlon, J.H., Pollock, T.L., Giberson, D.J., and Komadina-Douthwright, S. 1993. The Catamaran Brook (New Brunswick) habitat research project: biological, physical and chemical conditions (19901992). Can. Tech. Rep. Fish. Aquat. Sci. No. 1914.

Ferrari, M.C.O., Vavrek, M.A., Elvidge, C.K., Fridman, B., Chivers, D.P., and Brown, G.E. 2008. Sensory complementation and the acquisition of predator recognition by salmonid fishes. Behav. Ecol. Sociobiol. 63(1): 113-121. doi:10.1007/s00265-008-0641-1.

Flecker, A.S. 1992. Fish predation and the evolution of invertebrate drift periodicity: evidence from neotropical streams. Ecology, 73(2): 438-448. doi:10.2307/1940751. 
Fraser, N.H.C., and Metcalfe, N.B. 1997. The costs of becoming nocturnal: feeding efficiency in relation to light intensity in juvenile Atlantic salmon. Funct. Ecol. 11(3): 385-391. doi:10. 1046/j.1365-2435.1997.00098.x.

Fraser, N.H.C., Metcalfe, N.B., and Thorpe, J.E. 1993. Temperature dependent switch between diurnal and nocturnal foraging in salmon. Proc. R. Soc. Lond. B Biol. Sci. 252(1334): 135-139. doi:10.1098/rspb.1993.0057.

Fraser, N.H.C., Metcalfe, N.B., , Heggenes, J., and Thorpe, J.E. 1995. Low summer temperatures cause juvenile Atlantic salmon to become nocturnal. Can. J. Zool. 73(3): 446-451. doi:10.1139/ z95-051.

Gries, G., Whalen, K.G., Juanes, F., and Parrish, D.L. 1997. Nocturnal activity of juvenile Atlantic salmon (Salmo salar) in late summer: evidence of diel activity partitioning. Can. J. Fish. Aquat. Sci. 54(6): 1408-1413. doi:10.1139/cjfas-54-6-1408.

Hartman, E.J., and Abrahams, M.V. 2000. Sensory compensation and the detection of predators: the interaction between chemical and visual information. Proc. R. Soc. Lond. B Biol. Sci. No. 267(1443): 571-575. doi:10.1098/rspb.2000.1039.

Helfman, G.S. 1989. Threat-sensitive predator avoidance in damselfish-trumpetfish interactions. Behav. Ecol. Sociobiol. 24(1): 47-58. doi:10.1007/BF00300117.

Imre, I., and Boisclair, D. 2004. Age effects on diel activity patterns on juvinile Atlantic salmon: parr are more nocturnal than young-of-the-year. J. Fish Biol. 64(6): 1731-1736. doi:10.1111/ j.0022-1112.2004.00417.x.

Johnston, T.A. 1997. Downstream movements of young-of-the-year fishes in Catamaran Brook and the Little Southwest Miramichi River, New Brunswick. J. Fish Biol. 51(5): 1047-1062. doi:10. 1111/j.1095-8649.1997.tb01543.x.

Keeley, E.R., and Grant, J.W. 1995. Allometric and environmental correlates of territory size in juvenile Atlantic salmon (Salmo salar). Can. J. Fish. Aquat. Sci. 52(1): 186-196. doi:10.1139/ f95-019.

Kim, J.-W., Brown, G.E., Dolinsek, I.J., Brodeur, N.N., Leduc, A.O.H.C., and Grant, J.W.A. 2009. Combined effects of chemical and visual information in eliciting antipredator behaviour in juvenile Atlantic salmon Salmo salar. J. Fish Biol. 74(6): 12801290. doi:10.1111/j.1095-8649.2009.02199.x.

Kronfeld-Schor, N., and Dayan, T. 2003. Partitioning of time as an ecological resource. Annu. Rev. Ecol. Syst. 34(1): 153-181. doi:10.1146/annurev.ecolsys.34.011802.132435.

Leduc, A.O.H.C., Roh, E., Breau, C., and Brown, G.E. 2007. Learned recognition of a novel odour by wild juvenile Atlantic salmon (Salmo salar) under fully natural conditions. Anim. Behav. 73(3): 471-477. doi:10.1016/j.anbehav.2006.09.005.

Lima, S.L., and Steury, T.D. 2005. Perception of predation risk: the foundation of nonlethal predator-prey interactions. In Ecology of predator-prey interactions. Edited by P. Barbosa and I. Castellanos. Oxford University Press, Oxford. pp. 166-188

Metcalfe, N.B., Fraser, N.H.C., and Burns, M.D. 1999. Food Availability and the nocturnal vs. diurnal foraging trade-off in juvenile salmon. J. Anim. Ecol. 68(2): 371-381. doi:10.1046/j.13652656.1999.00289.x.

Mirza, R.S., and Chivers, D.P. 2000. Predator-recognition training enhances survival of brook trout: evidence from laboratory and field-enclosure studies. Can. J. Zool. 78(12): 2198-2208. doi:10.1139/cjz-78-12-2198.

Mirza, R.S., and Chivers, D.P. 2003. Response of juvenile rainbow trout to varying concentrations of chemical alarm cue: response thresholds and survival during encounters with predators. Can. J. Zool. 81(1): 88-95. doi:10.1139/z02-216.

Orpwood, J.E., Griffiths, S.W., and Armstrong, J.D. 2006. Effects of food availability on temporal activity patterns and growth of Atlantic salmon. J. Anim. Ecol. 75(3): 677-685. doi:10.1111/j. 1365-2656.2006.01088.x. PMID:16689950.

Scott, W.B., and Crossman, E.J. 1973. Freshwater fishes of Canada. Fish. Res. Board. Can. Bull.

Smith, R.J.F. 1999. What good is smelly stuff in the skin? Cross function and cross taxa effects in fish "alarm substances". In Advances in chemical signals in vertebrates Edited by R.E. Johnston, D. Müller-Schwarze and P.W. Sorensen. Kluwer, New York. pp. 475-487.

Smith, M.E., and Belk, M.C. 2001. Risk assessment in western mosquitofish (Gambusia affinis): do multiple cues have additive effects? Behav. Ecol. Sociobiol. 51(1): 101-107. doi:10.1007/ s002650100415.

Smith, R.W., and Griffith, J.S. 1994. Survival of rainbow trout during their first winter in the Henrys Fork of the Snake River, Idaho. Trans. Am. Fish. Soc. 123(5): 747-756. doi:10.1577/ 1548-8659(1994)123<0747:SORTDT>2.3.CO;2.

Steingrímsson, S.Ó., and Grant, J.W.A. 2003. Patterns and correlates of movement and site fidelity in individually tagged young-off-the-year Atlantic salmon (Salmo salar). Can. J. Fish. Aquat. Sci. 60(2): 193-202. doi:10.1139/f03-012.

Wood, C.C. 1987. Predation of juvenile Pacific salmon by the common merganser (Mergus merganser) on eastern Vancouver Island. II: Predation of stream-resident juvenile salmon by merganser broods. Can. J. Fish. Aquat. Sci. 44(5): 950-959. doi:10.1139/f87-113. 